\title{
Comparative analysis of clinical, treatment, and survival characteristics of signet ring cell and adenocarcinoma of esophagus
}

\author{
Zhang Peng, Feng Li, Zeng Cheng, Wu Kai, Zhao Song \\ Department of Thoracic Surgery, The First Affiliated Hospital of Zhengzhou University, Zhengzhou, China \\ Contributions: (I) Conception and design: Z Peng, F Li; (II) Administrative support: Z Song, W Kai; (III) Provision of study materials or patients: Z \\ Peng; (IV) Collection and assembly of data: Z Peng, Z Cheng; (V) Data analysis and interpretation: Z Peng; (VI) Manuscript writing: All authors; (VII) \\ Final approval of manuscript: All authors. \\ Correspondence to: Zhao Song, MD. Department of Thoracic Surgery, The First Affiliated Hospital of Zhengzhou University, No.1 Jianshe East Road, \\ Erqi District, Zhengzhou, China. Email: zhaosong@zzu.edu.cn.
}

Background: Signet ring cell carcinoma (SRC) is a rare pathological subtype of mucinous adenocarcinoma (AC). Clinical features, prognosis, and especially treatment methods between SRC and AC of the esophagus remain controversial. Thus, we conducted this study to explore the differences in clinicopathological characteristics and treatment modalities between SRC and AC of the esophagus.

Methods: A retrospective cohort study based on the Surveillance, Epidemiology, and End Results (SEER) program database was conducted. Patients diagnosed with SRC or AC not otherwise specified (NOS) were selected between 2004 and 2018. We investigated the prognosis of SRC and AC in terms of overall survival (OS). A subgroup analysis was performed according to the stage and different treatment methods.

Results: A total of 24,987 patients were enrolled, including 1,147 with SRC and 23,840 with AC. In the multivariate Cox analysis of the whole cohort, SRC, tumor site, differentiation, metastases, American Joint Committee on Cancer (AJCC) 6th edition staging, treatment, tumor size, lymph nodes examined, and positive lymph nodes were independent risk factors. The results of the subgroup analysis showed that surgery alone was associated with better OS for AC at the early stage, but was not significantly different for SRC (P=0.896). Surgery plus adjuvant therapy was the best treatment for SRC and AC at the late stage. In the multivariate Cox analysis, the treatment of surgery plus adjuvant therapy had a tendency towards better OS at the early stage [hazard ratio (HR): 0.64, 95\% confidence interval (CI): 0.39-1.1, P=0.08].

Conclusions: SRC is an independent risk factor, with a higher grade of differentiation, later stage, larger tumor size, more positive lymph nodes, and poorer prognosis compared with AC. Surgery plus adjuvant therapy seems to be useful for SRC at the early stage, but further research is needed.

Keywords: Signet ring cell carcinoma of the esophagus; esophagus carcinoma; treatment; prognosis

Submitted Jul 15, 2021. Accepted for publication Aug 10, 2021.

doi: 10.21037/jgo-21-445

View this article at: https://dx.doi.org/10.21037/jgo-21-445

\section{Introduction}

Esophageal cancer (EC) is a common malignancy, currently ranking 7 th in morbidity and 6th in mortality worldwide, with an average of 572,000 new cases and 509,000 deaths per year (1). EC is mainly divided into esophageal squamous cell carcinoma (ESCC) and adenocarcinoma (AC), of which the incidence of $\mathrm{AC}$ is increasing year by year and is more common in high-income developed countries, such as the United States, Australia, France, and the United Kingdom (1). The National Comprehensive Cancer Network (NCCN) guidelines recommend neoadjuvant 
chemoradiotherapy plus radical surgery for locally advanced AC (2), although the overall survival (OS) of AC is still not ideal (3).

Signet ring cell carcinoma (SRC) is a rare pathological subtype of mucinous AC characterized by a large accumulation of intracellular mucus that pushes the nucleus to one side, creating a signet ring-like appearance (4). The World Health Organization (WHO) classifies isolated or small groups of malignant cells with mucin in more than $50 \%$ of the tumor cell mass as SRC, and those with less than 50\% are still classified as AC (5). Although SRC has been found in a variety of organs in the human body, including the breast, lung, and bladder (6), the upper digestive tract is still a common site of occurrence, with the incidence of esophageal SRC reported to be less than $10 \%(7,8)$. Through many small-scale studies, it has been found that esophageal SRC has poor pathomorphological characteristics, and is often staged late, is insensitive to neoadjuvant therapy, has a high positive surgical margin rate, and has a poor prognosis $(6,8-14)$, and endoscopic resection for early esophageal SRC appears to be less effective (15). These characteristics have brought great challenges to treatment. In the face of esophageal SRC, should we adopt different treatment methods from AC? It is not clear what the specific treatment strategies are.

In 1973, the National Cancer Institute established the Surveillance, Epidemiology, and End Results (SEER) program to provide information on cancer patients for research. Covering approximately $28 \%$ of the tumor population and consisting of 18 cancer registries that contain information on cancer incidence and mortality in the United States, it is ideally suited for retrospective exploration of rare tumors. There have been several previous studies on esophageal SRC using the SEER database $(7,16,17)$, among which the results of Yendamuri et al. suggested that the prognosis of esophageal SRC was worse than that of $\mathrm{AC}$ in both the whole cohort and the surgical cohort, and surgery plus radiotherapy could improve the survival of the entire cohort. However, whether the specific treatment could improve the OS in different stage was unknown. Wu et al. found that esophageal SRC had a worse survival compared to gastric SRC, but the effect of different treatments on survival had not been elucidated. What's more, neither of the two studies included chemotherapy. Another study by Wan et al. only investigated the difference in prognosis between different clinicopathological features and treatment modalities of esophageal SRC. To our knowledge, there is currently a lack of reliable evidence for differences in clinicopathological features and treatment strategies between ESRC and AC. In this study, the SEER database was used to explore the differences between various features of ESRC and AC, in an attempt to find the best treatment for ESRC. We present the following article in accordance with the STROBE reporting checklist (available at https://dx.doi.org/10.21037/ jgo-21-445).

\section{Methods}

\section{Patient selection}

All case data in this study (SRC and AC) were collected from the SEER database established by the National Cancer Institute (https://seer.cancer.gov/). SEER* STAT software (SEER* STAT, V8.3.6) was used to search the data. To obtain complete chemotherapy information, TNM staging [American Joint Committee on Cancer (AJCC) 6th edition], and distant metastasis information, we selected the years of diagnosis between 2004 and 2018 as these important variables were only available since 2004 . The inclusion criteria were as follows: (I) the tumor site was the esophagus; (II) histological codes (International Classification of Cancer Diseases 3rd edition, ICD-O-3) were used to identify the 2 pathological types, namely AC not otherwise specified (NOS): 8140 and SRC: 8490 (7); (III) the year of screening and diagnosis was from 2004 to 2018. The exclusion criteria were as follows: (I) unknown race information; (II) survival information was unknown. Figure 1 shows the patient selection process. This study was conducted in accordance with the Declaration of Helsinki (as revised in 2013).

\section{Variables}

We included as much information as possible in the screening of patients to ensure that the final results were true and accurate, without selection bias, including baseline demographics (age, sex, race, life status, months of survival), tumor characteristics (pathological type, tumor location, differentiation, TNM stage of the AJCC 6th edition, tumor size, number of lymph nodes examined, number of positive lymph nodes), and surgery, radiotherapy, and chemotherapy information. Age was expressed as mean \pm standard deviation (SD). Tumor size, the number of nodes examined and positive were divided into several subgroups. Tumor location information was reclassified into 


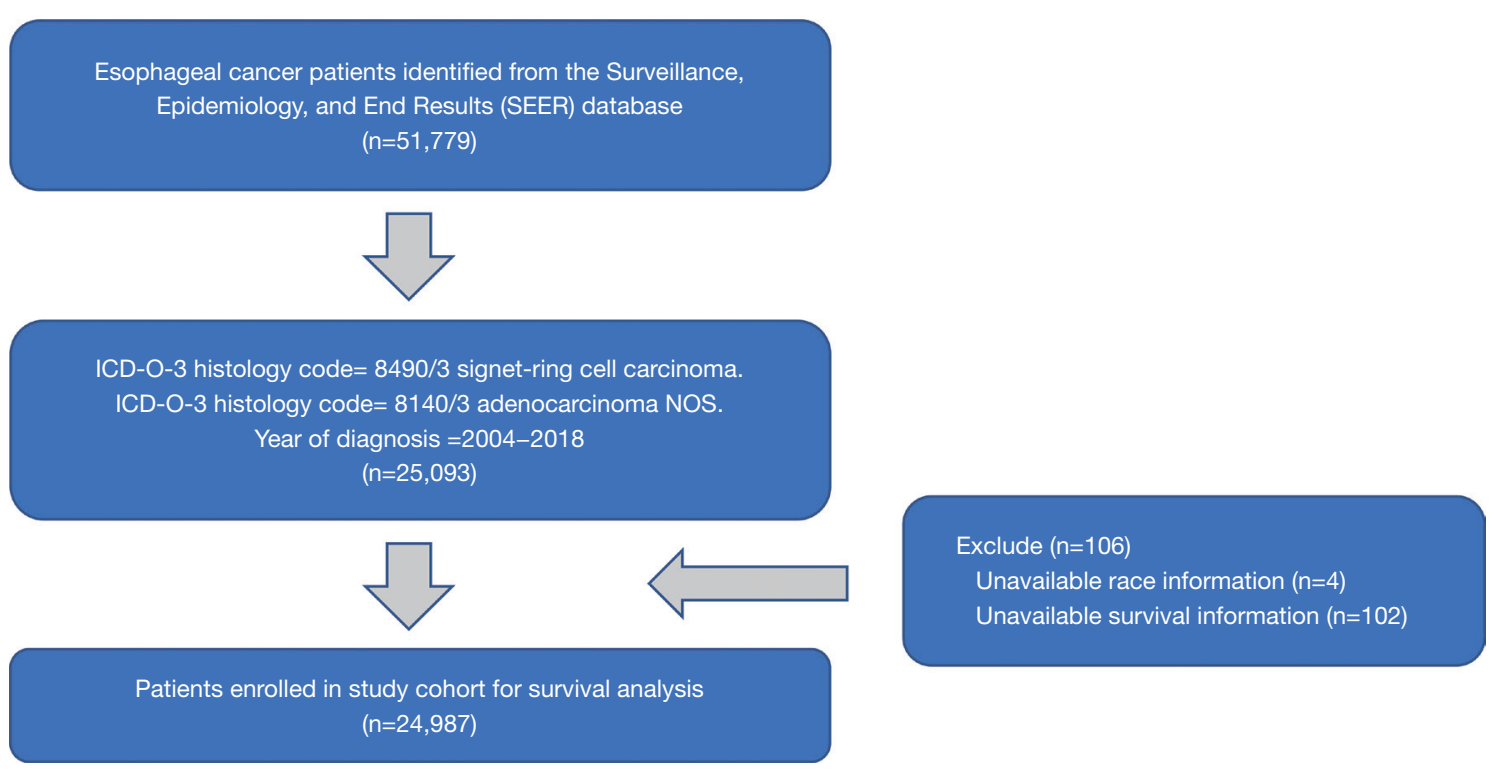

Figure 1 Study diagram of the selection process.

upper third, middle third, lower third, overlapping, and esophagus NOS, among which cervical tumors were placed in the upper third, thoracic tumors in the middle third, and abdominal tumors in the lower third. The treatment methods were re-divided into 4 groups: none, adjuvant only, surgery only, and surgery + adjuvant. Adjuvant included chemotherapy, radiotherapy, or chemoradiotherapy. The primary endpoint of this study was OS. "Survival Months" contained survival time information. Based on Vital Status Recode, the OS from the first diagnosis to death from any cause was calculated. As far as we know, this is the largest study of comparative analysis of SRC and AC of esophagus.

\section{Statistical analysis}

Continuous variables were analyzed by Student's $t$-test. Categorical variables were analyzed by the chi-square test or Fisher's exact test. Univariate analysis was performed on the OS of the entire cohort and subgroups using the Cox proportional hazards model. Variables with $\mathrm{P}<0.1$ were included in the multivariate analysis, the hazard ratio (HR) and corresponding $95 \%$ confidence interval (CI) were calculated, and a multivariate Cox forest plot was generated using the "forestplot" package. Survival curves were plotted using the Kaplan-Meier method and the "ggplot2" package, and the log-rank test was performed using the "Survival" package for comparison. Missing data was divided as a subgroup in the analysis, while those without follow-up information were excluded. All analyses were performed using IBM SPSS Statistics 26.0 (IBM Corp., Armonk, NY, USA) and R version 4.0.5 (The R Project for Statistical Computing, Vienna, Austria). Two-sided P values $<0.05$ were assessed as statistically significant. All missing data would be analyzed as a separate group.

\section{Results}

\section{Patient characteristics}

In total, 25,093 patients were diagnosed as SRC or AC from SEER database, then 106 patients were excluded as unavailable race information (4 patients) and survival information (102 patients). Finally, a total of 24,987 patients met the inclusion criteria from the SEER database, including 1,147 patients with SRC (4.6\%) and 23,840 patients with AC (95.4\%). The number of participants with missing data in differentiation, stage, tumor size, nodes examined and nodes positive were $6,082,7,903,11,078,823,18,622$ respectively. The overall cohort characteristics of the 2 pathological types are compared in Table 1. Consistent with a former study (7), gender (male: $86.4 \%$ vs. $86.1 \%$ ), age $(65.7 \pm 11.9$ vs. $65.7 \pm 11.9)$, race (White: $93.5 \%$ vs. $94.1 \%$ ), and other baseline characteristics showed no statistically significant differences. A significant difference was found in terms of the tumor location, as SRC was found more 
Table 1 Demographic, tumor, and treatment characteristics of the study population

\begin{tabular}{|c|c|c|c|}
\hline Variables & $\operatorname{SRC}(n=1,147)$ & $A C(n=23,840)$ & $P$ value \\
\hline \multicolumn{3}{|l|}{ Gender, n (\%) } & 0.823 \\
\hline Male & $991(86.4)$ & $20,527(86.1)$ & - \\
\hline Female & $156(13.6)$ & $3,313(13.9)$ & - \\
\hline Age, mean \pm SD & $65.7 \pm 11.9$ & $65.7 \pm 11.9$ & 0.761 \\
\hline \multicolumn{3}{|l|}{ Race, n (\%) } & 0.326 \\
\hline White & $1073(93.5)$ & $22,526(94.1)$ & \\
\hline Black & $34(2.9)$ & $650(2.7)$ & \\
\hline Other & $40(3.5)$ & $664(2.8)$ & \\
\hline \multicolumn{3}{|l|}{ Tumor site, n (\%) } & $<0.001$ \\
\hline Upper & $8(0.7)$ & $264(1.1)$ & \\
\hline Middle & $64(5.6)$ & $1,815(7.6)$ & \\
\hline Lower & $953(83.1)$ & $18,780(78.8)$ & \\
\hline Overlapping & $56(4.9)$ & $942(4.0)$ & \\
\hline $\begin{array}{l}\text { Esophagus, } \\
\text { NOS }\end{array}$ & $66(5.8)$ & $2,039(8.6)$ & \\
\hline \multicolumn{3}{|l|}{ Differentiation, n (\%) } & $<0.001$ \\
\hline Well & $2(0.2)$ & $1,092(4.6)$ & \\
\hline Moderate & $30(2.6)$ & $7,338(30.8)$ & \\
\hline Poor & $890(77.6)$ & $9,310(39.1)$ & \\
\hline Undifferentiation & $21(1.8)$ & $222(0.9)$ & \\
\hline Unknown & $204(17.8)$ & $5,878(24.7)$ & \\
\hline \multicolumn{3}{|c|}{ Pathological T stage, n (\%) } & $<0.001$ \\
\hline T0-T2 & $298(26.0)$ & $6,746(28.3)$ & \\
\hline T3-T4 & $489(42.6)$ & $7,370(30.9)$ & \\
\hline TX & $360(31.4)$ & $9,724(40.8)$ & \\
\hline \multicolumn{3}{|c|}{ Pathological N stage, n (\%) } & $<0.001$ \\
\hline No & $357(31.1)$ & $7,514(31.5)$ & \\
\hline N1 & 509 (44.4) & $8,436(35.4)$ & \\
\hline NX & $281(24.5)$ & $7,890(33.1)$ & \\
\hline \multicolumn{3}{|c|}{ Pathological M stage, n (\%) } & $<0.001$ \\
\hline Mo & $561(48.9)$ & $10,068(42.2)$ & \\
\hline M1 & $342(29.8)$ & $7,143(30.0)$ & \\
\hline $\mathrm{MX}$ & $244(21.3)$ & $6,629(27.8)$ & \\
\hline
\end{tabular}

Table 1 (continued)
Table 1 (continued)

\begin{tabular}{|c|c|c|c|}
\hline Variables & $\operatorname{SRC}(n=1,147)$ & $A C(n=23,840)$ & $P$ value \\
\hline \multicolumn{3}{|l|}{ Stage, n (\%) } & $<0.001$ \\
\hline 1 & $103(9.0)$ & 2,757 (11.6) & \\
\hline II & $163(14.2)$ & 2,992 (12.6) & \\
\hline III & $241(21.0)$ & $3,343(14.0)$ & \\
\hline IV & $342(29.8)$ & $7,143(30.0)$ & \\
\hline Unknown & $298(26.0)$ & 7,605 (31.9) & \\
\hline \multicolumn{3}{|l|}{ Treatment } & $<0.001$ \\
\hline None & 232 (20.2) & 4,946 (20.7) & \\
\hline Adjuvant only & $573(50.0)$ & $11,668(48.9)$ & \\
\hline Surgery only & $65(5.7)$ & $2,370(9.9)$ & \\
\hline $\begin{array}{l}\text { Surgery + } \\
\text { adjuvant }\end{array}$ & $277(24.1)$ & $4,856(20.4)$ & \\
\hline \multicolumn{3}{|l|}{ Tumor size, n (\%) } & $<0.001$ \\
\hline $0-3 \mathrm{~cm}$ & $142(12.4)$ & 4,331 (18.2) & \\
\hline $3-6 \mathrm{~cm}$ & $288(25.1)$ & $5,617(23.6)$ & \\
\hline $6-9 \mathrm{~cm}$ & $157(13.7)$ & $2,175(9.1)$ & \\
\hline$>9 \mathrm{~cm}$ & $79(6.9)$ & $1,120(4.7)$ & \\
\hline Unknown & $481(41.9)$ & $10,597(44.5)$ & \\
\hline \multicolumn{3}{|c|}{ Nodes examined, n (\%) } & 0.737 \\
\hline 0 & $788(68.7)$ & $16,596(69.6)$ & \\
\hline $1-5$ & $79(6.9)$ & $1,639(6.9)$ & \\
\hline $6-10$ & $50(4.4)$ & $1,191(5.0)$ & \\
\hline $11-15$ & $67(5.8)$ & $1,259(5.3)$ & \\
\hline $16-20$ & $52(4.5)$ & $969(4.1)$ & \\
\hline$>20$ & $76(6.6)$ & $1,398(5.9)$ & \\
\hline Unknown & $35(3.1)$ & $788(3.3)$ & \\
\hline \multicolumn{3}{|c|}{ Nodes positive, n (\%) } & $<0.001$ \\
\hline 0 & $140(12.2)$ & $3,681(15.4)$ & \\
\hline $1-2$ & $79(6.9)$ & $1,402(5.9)$ & \\
\hline $3-4$ & $28(2.4)$ & $451(1.9)$ & \\
\hline $5-6$ & $22(1.9)$ & $206(0.9)$ & \\
\hline$\geq 7$ & $35(3.1)$ & 321 (1.3) & \\
\hline Unknown & $843(73.5)$ & $17,779(74.6)$ & \\
\hline
\end{tabular}

NOS, not otherwise specified. 


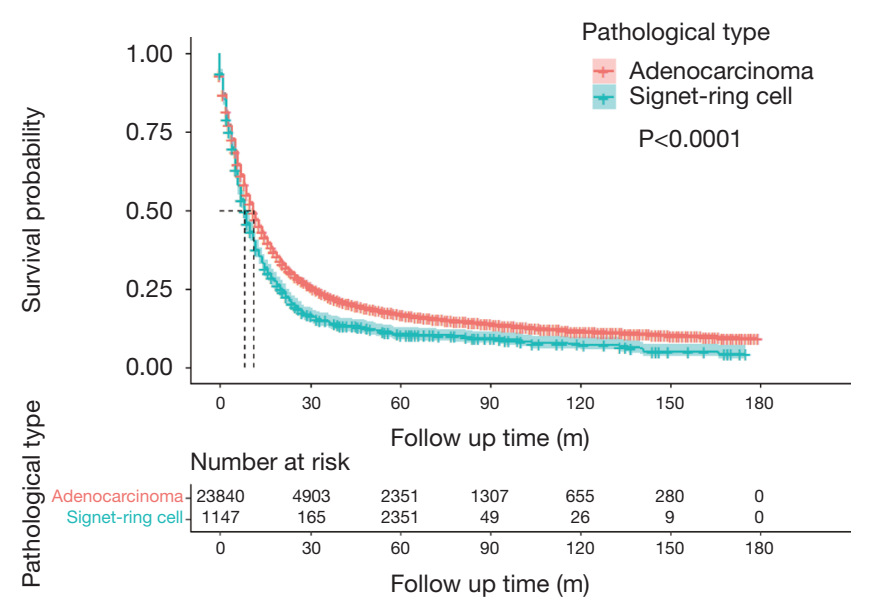

Figure 2 Kaplan-Meier curves of the association between pathological type and overall survival in the whole cohort.

frequently in the lower third ( $83.1 \%$ vs. $78.8 \%)$, whereas AC was more likely to be found in the middle third (5.6\% vs. $7.6 \%)(\mathrm{P}<0.001)$, although both pathological types were mostly in the lower position. In addition, SRC tended to have more advanced differentiation, with poor or undifferentiation accounting for $79.4 \%$, while $\mathrm{AC}$ with poor or undifferentiation only accounted for $40.0 \%(\mathrm{P}<0.001)$. In terms of TNM staging, SRC was more present in the middle and late stages (stage I: $9.0 \%$ vs. $11.6 \%$, stage II: $14.2 \%$ vs. 12.6 , stage III: $21.0 \%$ vs. 14.0 , stage IV: $29.8 \%$ vs. $30.0 \%)(\mathrm{P}<0.001)$. In terms of treatment, $20.2 \%$ of SRC and $20.7 \%$ of AC patients did not receive any treatment, and $50.0 \%$ of SRC and $48.9 \%$ of AC patients only received adjuvant treatment. Patients with AC were more likely to have surgery alone ( $5.7 \%$ vs. $9.9 \%)$, and patients with surgery plus adjuvant therapy were more likely to have SRC (24.1\% vs. $20.4 \%)(\mathrm{P}<0.001)$. In the comparison of tumor size, SRC was significantly higher than AC in each group

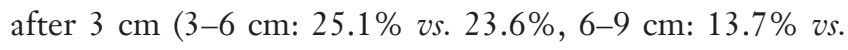
$9.1 \%,>9 \mathrm{~cm}: 6.9 \%$ vs. $4.7 \%)$, and the proportion of SRC was lower than $\mathrm{AC}$ in the $0-3 \mathrm{~cm}$ range (12.4\% vs. $18.2 \%)$ $(\mathrm{P}<0.001)$. In terms of lymph nodes examined, SRC was higher than AC in each group of more than 10 (11-15: $5.8 \%$ vs. $5.3 \%, 16-20: 4.5 \%$ vs. $4.1 \%,>20: 6.6 \%$ vs. $5.9 \%)$, and the 3 groups of 10 or less were less than (0: $68.7 \%$ vs. $69.6 \%, 6-10: 4.4 \%$ vs. $5.0 \%)$ or equal to $(1-5: 6.9 \%$ vs. $6.9 \%)$ the AC group $(\mathrm{P}<0.001)$. The proportion of positive lymph nodes in the SRC group was greater than that of the AC group $(\mathrm{P}<0.001)$, which also corroborates the results of late stage SRC.

\section{Survival and prognostic factors in the whole cohort}

The median OS time for the whole cohort was 11 months (IQR 4-31), the median OS of the SRC group was 8 months (IQR 4-21), and the median OS of the AC group was 11 months (IQR 4-32). The 3-year and 5-year OS of the SRC group were $14.4 \%$ (95\% CI: $0.12-0.17$ ) and $11 \%$ (95\% CI: 0.09-0.13), respectively. The 3-year and 5-year OS of the AC group were $22.8 \%$ (95\% CI: $0.22-0.23$ ) and $17.0 \%$ (95\% CI: $0.17-0.18)$, respectively. Figure 2 shows the results of log-rank tests conducted to evaluate the OS of SRC and AC, and the results showed that the SRC group had a lower OS $(\mathrm{P}<0.0001)$, which was also demonstrated across the 4 stages (Figure 3). Then, meaningful variables were included in the univariate analysis, and the final results (Table 2) showed that SRC pathological types, increased age, tumor location of middle and overlapping, as well as high-grade differentiation were associated with worse OS. Distant metastasis, high-grade stage, no treatment, adjuvant therapy alone, surgery plus adjuvant therapy, large tumor size, and more positive lymph nodes were associated with lower OS and were independent predictors. However, a higher number of lymph node dissections was beneficial to OS.

\section{Differences in prognosis based on treatments for SRC and $A C$ in different stages}

Table 3 shows the different treatment regimens for SRC and AC at each stage. The results showed that the SRC group was more likely to receive surgery combined with adjuvant therapy, regardless of early (stage I-II) $(30.1 \%$ vs. $26.8 \%)$ or late stage (stage III-IV) $(25.7 \%$ vs. $18.8 \%)(\mathrm{P}<0.001)$. The AC group at the early stage was more likely to receive surgery alone than the SRC group (28.6\% vs. 14.7$)$, but at the late stage the $\mathrm{AC}$ group was more likely to receive adjuvant therapy alone than the SRC group $(60.7 \%$ vs. $55.1 \%)(\mathrm{P}<0.001)$. Figure 4 shows the effect of different treatment methods on the prognosis of the AC and SRC groups. It was clear that surgery alone had the best outcome for $\mathrm{AC}$ at the early stage $(\mathrm{P}<0.001)$ (Figure $4 B)$, while there was no statistically significant difference for SRC $(\mathrm{P}=0.896)$ (Figure 4A), Although the median survival of the SRC group combined with adjuvant therapy was shorter than that of surgery alone (36 vs. 44 months). The results (Figure $4 C, 4 D$ ) show that both groups had the best prognosis with surgery combined with adjuvant therapy $(\mathrm{P}<0.001)$. 
A

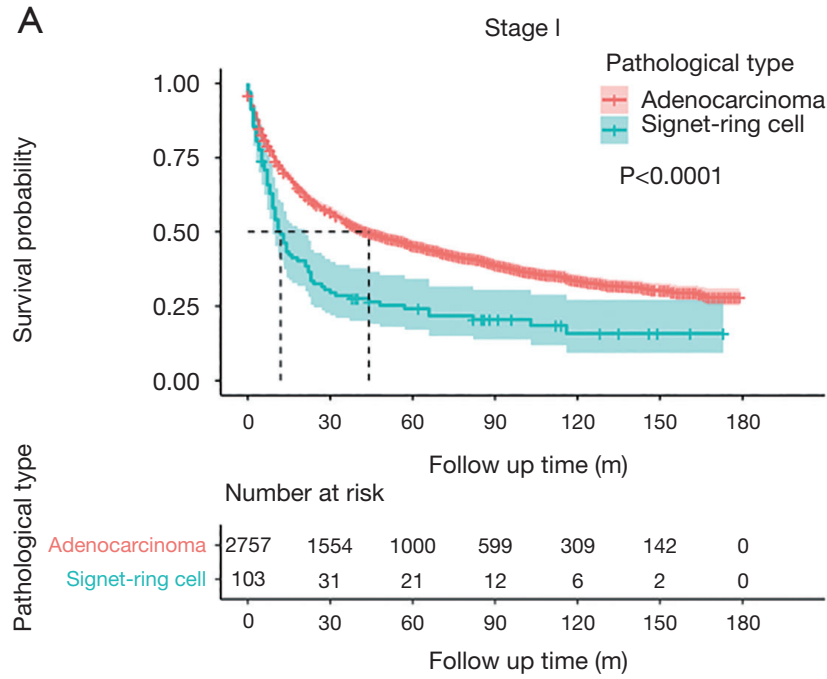

C

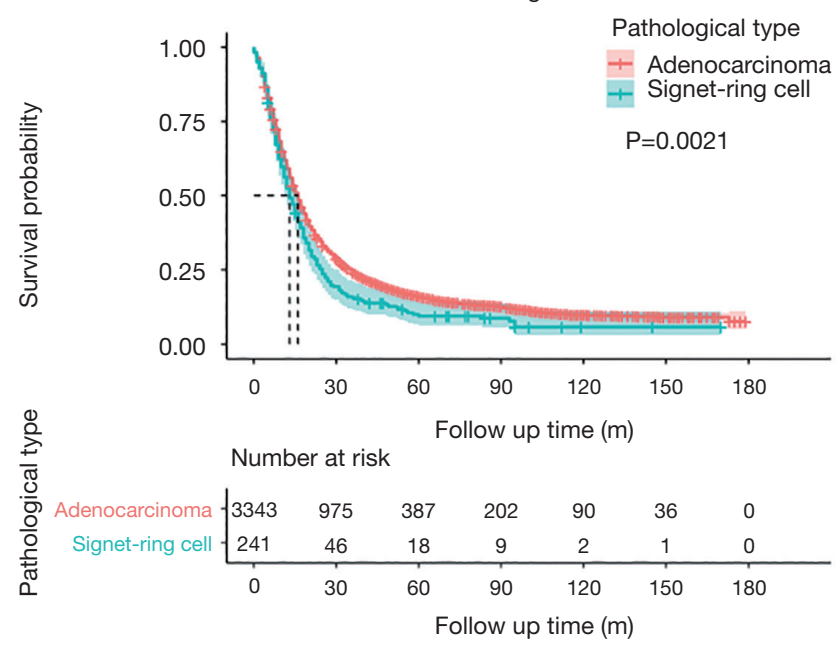

B

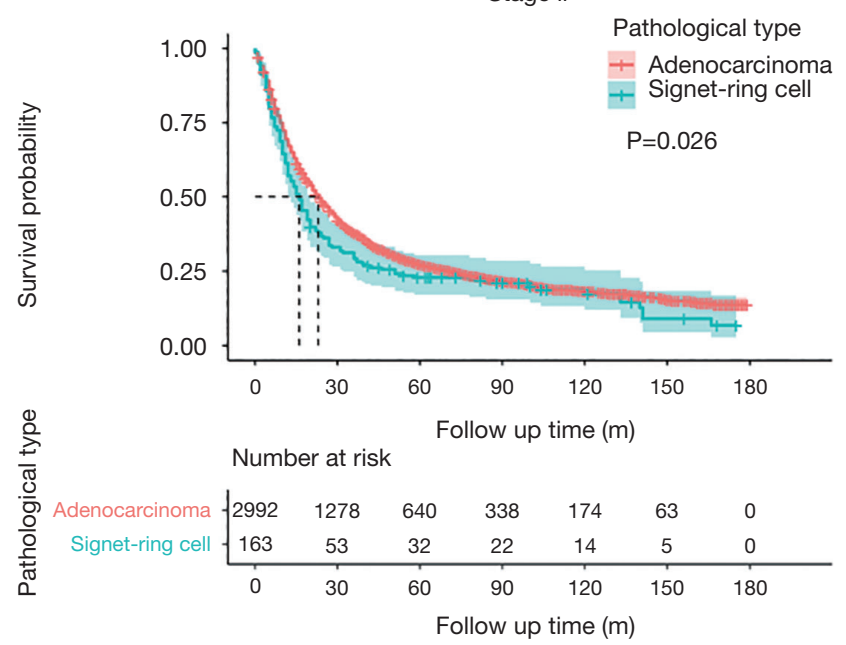

D

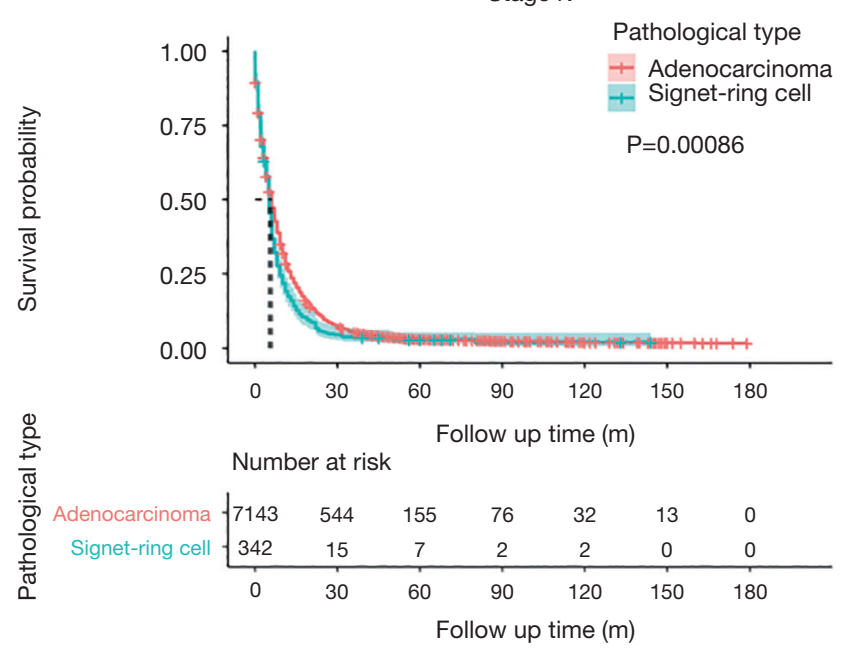

Figure 3 Kaplan-Meier curves of the association between pathological type and overall survival in different stage subgroup analyses.

\section{Survival and prognostic factors for SRC and AC in different stages}

At the early stage (stage I-II), the univariate Cox risk model showed that increased age, larger tumor size, fewer number of lymph nodes examined, and more positive lymph nodes in both groups were associated with lower OS. The difference was that in the AC group, women had worse OS than men (HR: 1.115, 95\% CI: 1.020-1.218, $\mathrm{P}=0.016$ ). In terms of treatment, with surgery alone as a reference, no treatment and adjuvant treatment alone were associated with poorer OS in both groups $(\mathrm{P}<0.001)$. However, surgery combined with adjuvant therapy tended to have a better OS in the SRC group (HR: 0.932, 95\% CI: 0.584-1.489), while surgery combined with adjuvant therapy was associated with worse OS in the AC group (HR: 1.803, 95\% CI: $1.634-$ $1.989, \mathrm{P}<0.001$ ) (Table 4). The multivariate Cox analysis (Figure 5) showed that larger tumor size and more positive lymph nodes were associated with lower OS in the 2 groups. In addition, in the AC group, increased age, the 3 other treatment methods, and less lymph node examinations were independent risk factors. None of the treatment methods in the SRC group were independent risk factors, but it is worth noting that surgery combined with adjuvant therapy had a tendency towards better OS than surgery alone (HR: 0.64, 95\% CI: 0.39-1.1; $\mathrm{P}=0.08)$. 
Table 2 Univariate and multivariate Cox analysis of risk factors of OS in the whole cohort

\begin{tabular}{|c|c|c|c|c|c|c|}
\hline Factors & \multicolumn{3}{|c|}{ Univariate } & \multicolumn{3}{|c|}{ Multivariate } \\
\hline \multicolumn{7}{|l|}{ Pathological type } \\
\hline Adenocarcinoma (Ref) & 1.396 & $1.171-1.660$ & $<0.001$ & 1.184 & $1.109-1.263$ & $<0.001$ \\
\hline Age & 1.018 & $1.017-1.019$ & $<0.001$ & 1.014 & $1.013-1.016$ & $<0.001$ \\
\hline \multicolumn{7}{|l|}{ White (Ref) } \\
\hline Black & 1.155 & $1.061-1.258$ & $<0.001$ & 1.063 & $0.976-1.158$ & 0.162 \\
\hline Other & 0.985 & $0.903-1.074$ & 0.725 & 0.874 & $0.801-0.953$ & 0.002 \\
\hline \multicolumn{7}{|l|}{ Gender } \\
\hline \multicolumn{7}{|l|}{ Tumor site } \\
\hline \multicolumn{7}{|l|}{ Upper (Ref) } \\
\hline Middle & 1.099 & $0.953-1.268$ & 0.196 & 1.166 & $1.011-1.346$ & 0.035 \\
\hline Lower & 0.968 & $0.846-1.108$ & 0.64 & 1.087 & $0.950-1.244$ & 0.226 \\
\hline Overlapping & 1.393 & $1.200-1.619$ & $<0.001$ & 1.290 & $1.109-1.499$ & 0.001 \\
\hline Esophagus NOS & 1.245 & $1.080-1.434$ & 0.002 & 1.078 & $0.935-1.243$ & 0.300 \\
\hline \multicolumn{7}{|l|}{ Differentiation } \\
\hline \multicolumn{7}{|l|}{ Well (Ref) } \\
\hline \multicolumn{7}{|l|}{ Pathological T stage } \\
\hline \multicolumn{7}{|l|}{ T0-T1 (Ref) } \\
\hline T2-T4 & 1.392 & $1.343-1.442$ & $<0.001$ & 1.030 & $0.983-1.080$ & 0.215 \\
\hline TX & 1.786 & $1.722-1.853$ & $<0.001$ & 1.178 & $1.118-1.241$ & $<0.001$ \\
\hline \multicolumn{7}{|l|}{ Pathological N stage } \\
\hline \multicolumn{7}{|l|}{ NO (Ref) } \\
\hline $\mathrm{N} 1$ & 1.443 & $1.396-1.492$ & $<0.001$ & 1.020 & $0.979-1.063$ & 0.354 \\
\hline NX & & & & 1.178 & $1.118-1.241$ & $<0.001$ \\
\hline \multicolumn{7}{|l|}{ Pathological M stage } \\
\hline \multicolumn{7}{|l|}{ M0 (Ref) } \\
\hline M1 & 2.639 & $2.554-2.727$ & $<0.001$ & 2.477 & $2.301-2.666$ & $<0.001$ \\
\hline$M X$ & & & & 1.066 & $0.982-1.156$ & 0.127 \\
\hline
\end{tabular}

Table 2 (continued) 
Table 2 (continued)

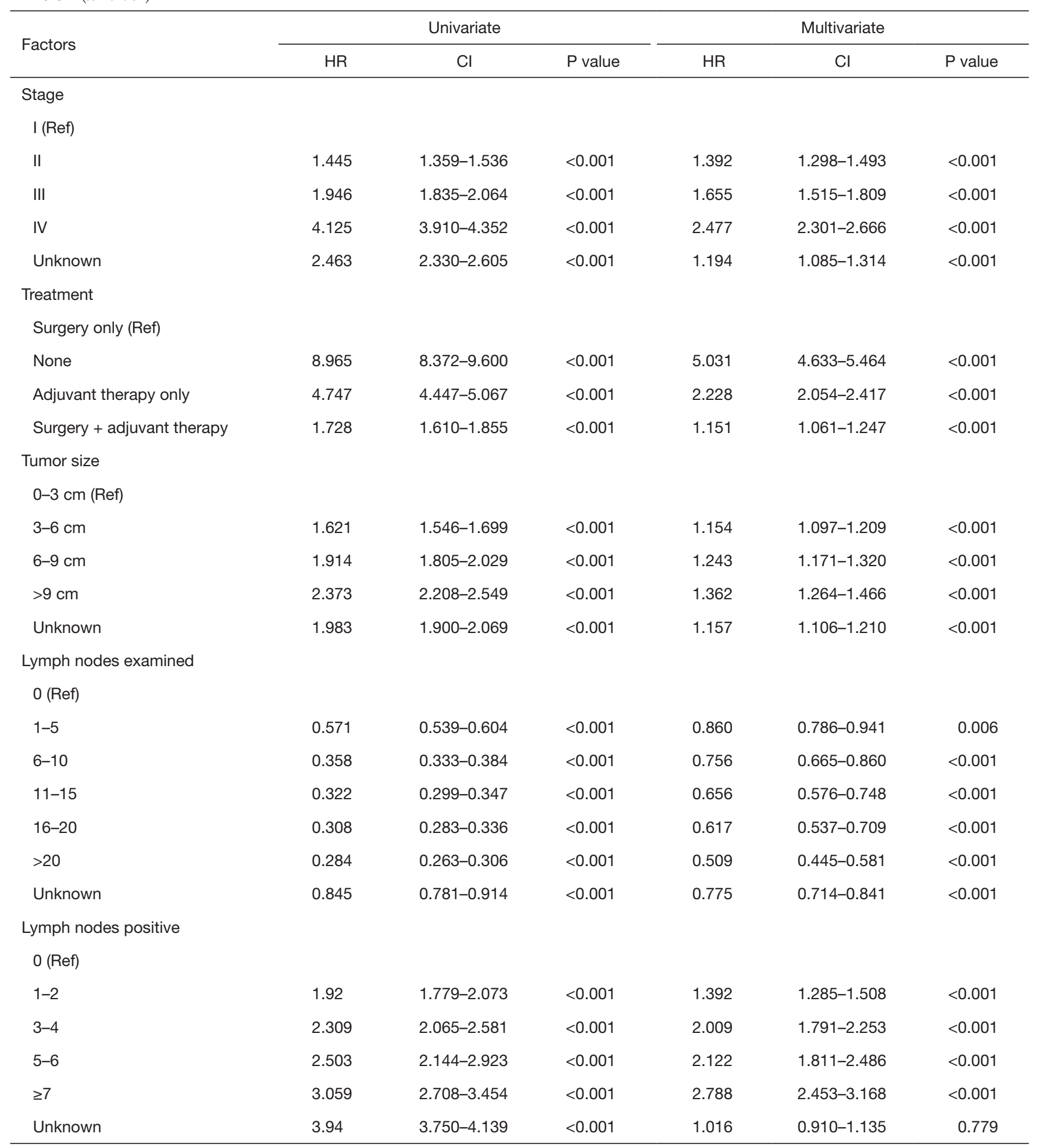

OS, overall survival; NOS, not otherwise specified. 
Table 3 Different treatments for SRC and AC in the early and late stages

\begin{tabular}{lccc}
\hline Variables & $\begin{array}{c}\text { SRC }(\mathrm{n}=849), \\
\mathrm{n}(\%)\end{array}$ & $\begin{array}{c}\mathrm{AC}(\mathrm{n}=16,235), \\
\mathrm{n}(\%)\end{array}$ & P value \\
\hline AJCC stage I-II & & & $<0.001$ \\
None & $33(12.4)$ & $792(13.8)$ & \\
Adjuvant only & $114(42.9)$ & $1,804(31.4)$ & \\
Surgery only & $39(14.7)$ & $1,610(28.0)$ & \\
Surgery + adjuvant & $80(30.1)$ & $1,543(26.8)$ & \\
AJCC stage III-IV & & & $<0.001$ \\
None & $94(16.1)$ & $1,931(18.4)$ & \\
Adjuvant only & $321(55.1)$ & $6,360(60.7)$ & \\
Surgery only & $18(3.1)$ & $220(2.1)$ & \\
Surgery + adjuvant & $150(25.7)$ & $1,975(18.8)$ & \\
\hline
\end{tabular}

SRC, signet ring cell carcinoma; AC, adenocarcinoma; AJCC, American Joint Committee on Cancer.

At the late stage (stage III-IV), univariate Cox analysis showed that increased age, no treatment, larger tumor size, less lymph node examinations, and more positive lymph nodes were all associated with worse OS. In the AC group, middle and overlapping tumor locations negatively impacted OS (Table 5). Figure 6 shows the results of the multivariate analysis for the 2 groups at the late stage. In terms of treatment, surgery combined with adjuvant therapy was a protective factor compared with surgery alone (SRC HR: 0.22, 95\% CI: 0.13-0.38, P<0.001; AC HR: 0.52, 95\% CI: $0.45-0.60, \mathrm{P}<0.001)$. Other variables such as age, no treatment, large tumor size, more lymph node examinations, and positive lymph nodes were all independent risk factors, while in the AC group, gender, race, and middle and overlapping tumor locations were independent risk factors.

\section{Discussion}

In this study, 1,147 cases of SRC and 23,840 cases of AC screened from 2004 to 2018 were compared using the SEER database, and the best treatment for the 2 different pathological types in different stages was discussed. The results showed that SRC was an independent prognostic factor in the overall cohort (HR: 1.184, 95\% CI: $1.109-$ $1.263, \mathrm{P}<0.001)$. In addition, although surgery combined with adjuvant therapy was the best treatment for both pathological types in the advanced tumor stage, the best treatment for patients with early SRC remains uncertain, and adjuvant treatment combined with surgery appears to have a tendency towards better prognosis compared with surgery alone (HR: 0.64, 95\% CI: 0.39-1.1, $\mathrm{P}=0.08$ ).

$\mathrm{SRC}$ is a rare pathological subtype of AC. According to the histological classification of gastrointestinal tumors formulated by WHO in 1990, SRC was classified as isolated or small groups of malignant cells with mucin in more than $50 \%$ of the tumor cell mass, and those with less than $50 \%$ are still classified as AC. Although the incidence is low, its clinicopathological features are worse than ordinary AC. A comprehensive meta-analysis showed that SRC pathological types predicted a worse prognosis (4), and a large number of studies demonstrated that SRC pathological types were independent prognostic factors $(6,8,14,18-20)$. Tumors with SRC ratios greater than $50 \%$ had a worse survival time, and had a lower 1 st, $3 \mathrm{rd}$, and 5 th year survival rate (8). In addition, the prognosis and treatment of SRC in different organs seems different. A study included SRC in 10 organs showed that SRC in bladder, breast, colon and rectum had better survival but SRC in esophagus gallbladder and pancreas had worse survival compared with stomach. Most of SRC of the bladder, breast, colon, gallbladder, rectal and small intestine received surgery and about one third of patients with esophageal and lung SRC received primary radiotherapy (17). However, the attention given to SRC is currently still not enough. And there is no difference in treatment between SRC and AC in our hospital. As far as we know, this study used the largest number of cases to date to compare SRC and AC. The results confirmed that SRC was an independent risk factor in the whole cohort, and the prognosis of SRC was worse than that of ordinary AC in the whole cohort and at each stage. Meanwhile, SRC had a large number of variables related to worse OS, such as later stage, poorer differentiation, larger tumor size, more positive lymph nodes, and other characteristics. We believe that this study challenges the Royal College of Pathologists statement on the standards of histopathological reporting of EC, which stated that including the presence of SRCs in the subclassification of tumors is not important (21), and therefore, we believe that adequate attention should be given to SRC to improve survival in this segment of patients.

The treatment is crucial to the prognosis of cancer patients. At present, the mainstream treatment for locally advanced AC is neoadjuvant chemoradiotherapy plus surgery, and several related studies have been carried out based on this. A study that included patients with both 
A

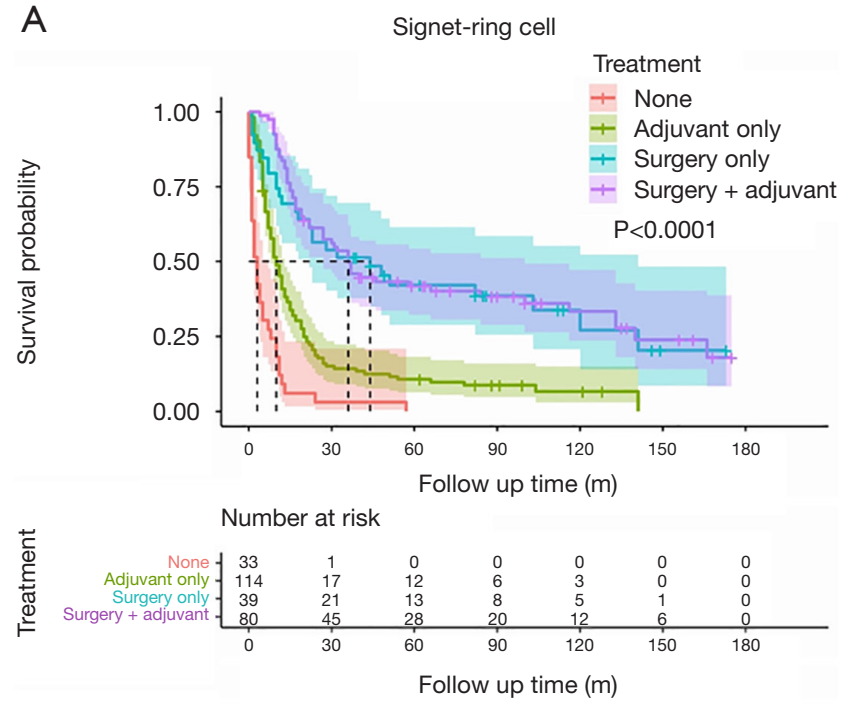

C
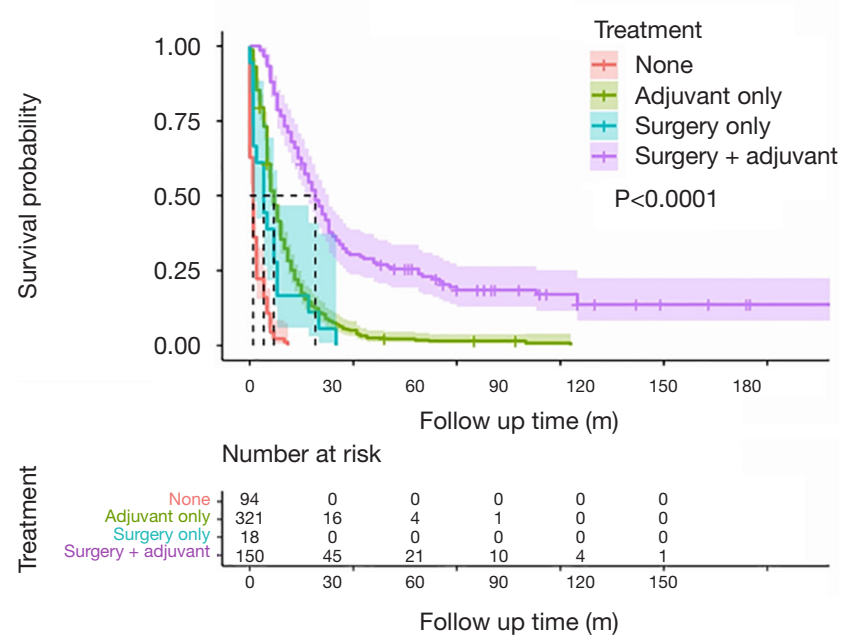

B
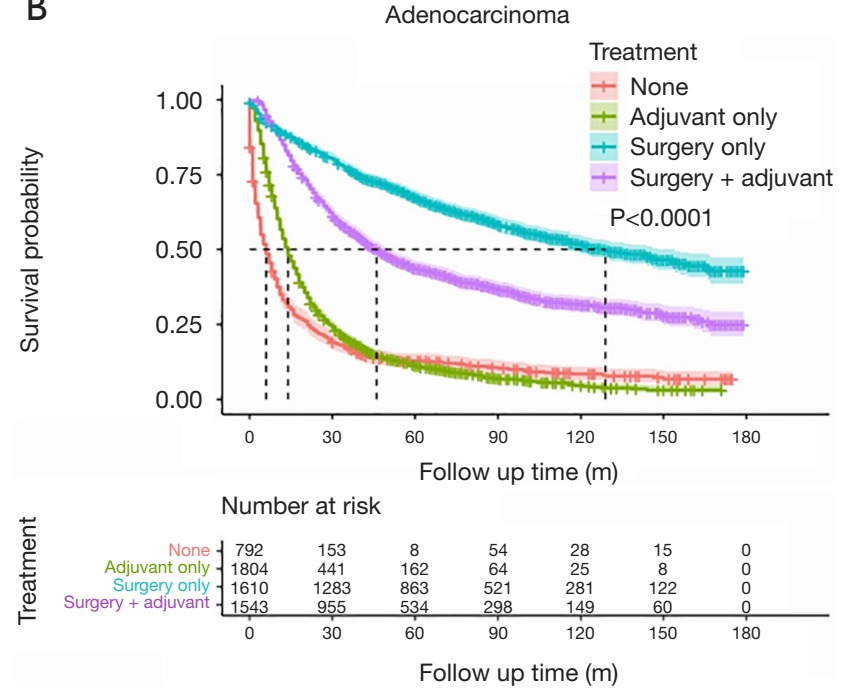

$\mathrm{D}$
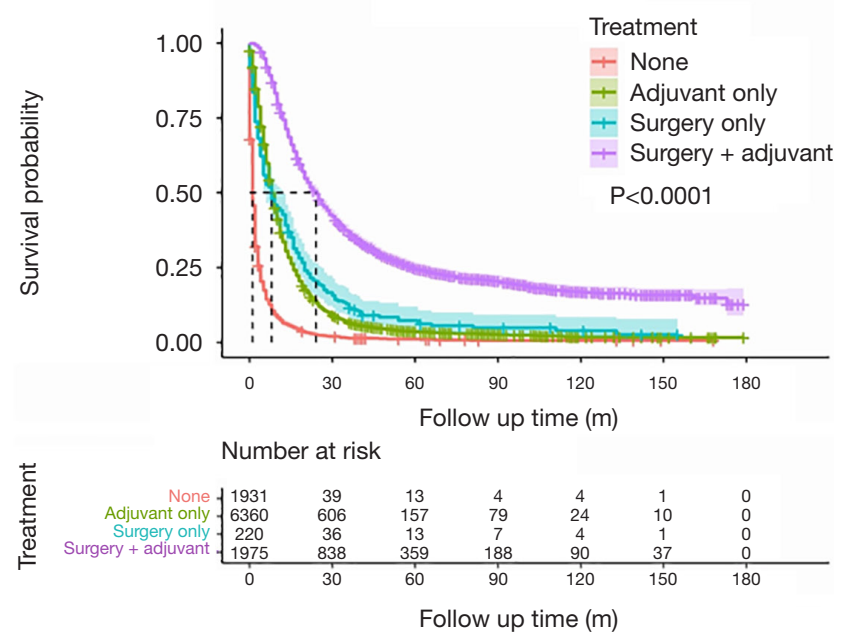

Figure 4 Kaplan-Meier curves of the effect of different treatments on the 2 pathological types and their association with overall survival in different stage subgroup analyses. (A) The prognosis of different treatments for SRC at the early stage; (B) the prognosis of different treatments for $\mathrm{AC}$ at the early stage; (C) the prognosis of different treatments for SRC at the late stage; (D) the prognosis of different treatments for AC at the late stage. SRC, signet-ring cell carcinoma; AC, adenocarcinoma.

SRC and mucinous histology suggested that preoperative chemoradiotherapy had a favorable outcome (18). Notably, the SRC type does not seem to respond significantly to neoadjuvant therapy (12-14), as $88.2 \%$ of patients with SRC showed minimal or no pathological response and only $27.8 \%$ were downstaged (10). However, other studies have shown that neoadjuvant chemoradiotherapy has a better prognosis than neoadjuvant chemotherapy, with no statistically significant difference in complete response rates $(9,11,22)$. A study that also used the SEER database to discuss the effect of treatment modality on SRC outcomes showed that the addition of radiotherapy to the surgical cohort was beneficial for survival (17). However, all the above studies only discussed the advantages and disadvantages of treatment methods in the whole cohort, and did not conduct a subgroup analysis of patients with different stages. Therefore, we believe that such studies are not of great significance, as it is known that stage is very important for the treatment methods of tumors. As shown by the results of the multivariate Cox risk model for the 
Table 4 Univariate Cox proportional hazard regression model analysis of risk factors of OS in the early stage

\begin{tabular}{|c|c|c|c|c|c|c|}
\hline Factors & \multicolumn{3}{|c|}{$\mathrm{SRC}$} & \multicolumn{3}{|c|}{$A C$} \\
\hline Age & 1.021 & $1.008-1.034$ & 0.001 & 1.039 & $1.036-1.042$ & $<0.001$ \\
\hline \multicolumn{7}{|l|}{ Race } \\
\hline \multicolumn{7}{|l|}{ White (Ref) } \\
\hline Other & 0.8 & $0.355-1.802$ & 0.590 & 0.933 & $0.753-1.155$ & 0.525 \\
\hline \multicolumn{7}{|l|}{ Gender } \\
\hline \multicolumn{7}{|l|}{ Male (Ref) } \\
\hline Female & 1.197 & $0.794-1.805$ & 0.391 & 1.115 & $1.020-1.218$ & 0.016 \\
\hline Lower & 4.967 & $0.690-35.745$ & 0.111 & 0.931 & $0.718-1.207$ & 0.588 \\
\hline Overlapping & 5.916 & $0.735-47.622$ & 0.095 & 1.201 & $0.878-1.644$ & 0.252 \\
\hline Esophagus NOS & 3.809 & $0.487-29.797$ & 0.203 & 1.048 & $0.791-1.390$ & 0.743 \\
\hline \multicolumn{7}{|l|}{ Treatment } \\
\hline \multicolumn{7}{|l|}{ Surgery only (Ref) } \\
\hline None & 7.457 & $4.375-12.711$ & $<0.001$ & 6.177 & $5.553-6.871$ & $<0.001$ \\
\hline Adjuvant therapy only & 2.638 & $1.704-4.082$ & $<0.001$ & 4.859 & $4.433-5.327$ & $<0.001$ \\
\hline Unknown & 2.195 & $1.504-3.205$ & $<0.001$ & 1.596 & $1.478-1.723$ & $<0.001$ \\
\hline \multicolumn{7}{|l|}{ Lymph nodes examined } \\
\hline \multicolumn{7}{|l|}{0 (Ref) } \\
\hline $1-10$ & 0.468 & $0.311-0.703$ & $<0.001$ & 0.511 & $0.470-0.556$ & $<0.001$ \\
\hline $11-20$ & 0.326 & $0.207-0.515$ & $<0.001$ & 0.371 & $0.336-0.411$ & $<0.001$ \\
\hline$>20$ & 0.276 & $0.149-0.512$ & $<0.001$ & 0.32 & $0.279-0.368$ & $<0.001$ \\
\hline Unknown & 0.482 & $0.211-1.103$ & 0.084 & 0.596 & $0.459-0.776$ & $<0.001$ \\
\hline \multicolumn{7}{|l|}{ Lymph nodes positive } \\
\hline \multicolumn{7}{|l|}{0 (Ref) } \\
\hline $1-6$ & 1.805 & $1.025-3.177$ & 0.041 & 1.67 & $1.462-1.907$ & $<0.001$ \\
\hline$\geq 7$ & 9.676 & $2.309-40.550$ & 0.002 & 3.356 & $2.105-5.349$ & $<0.001$ \\
\hline Unknown & 3.12 & $2.203-4.418$ & $<0.001$ & 2.605 & $2.425-2.799$ & $<0.001$ \\
\hline
\end{tabular}

OS, overall survival; NOS, not otherwise specified.

(C) Journal of Gastrointestinal Oncology. All rights reserved. $\quad$ f Gastrointest Oncol 202 1;12(4):1643-1660 I https://dx.doi.org/10.21037/jgo-21-445 
A

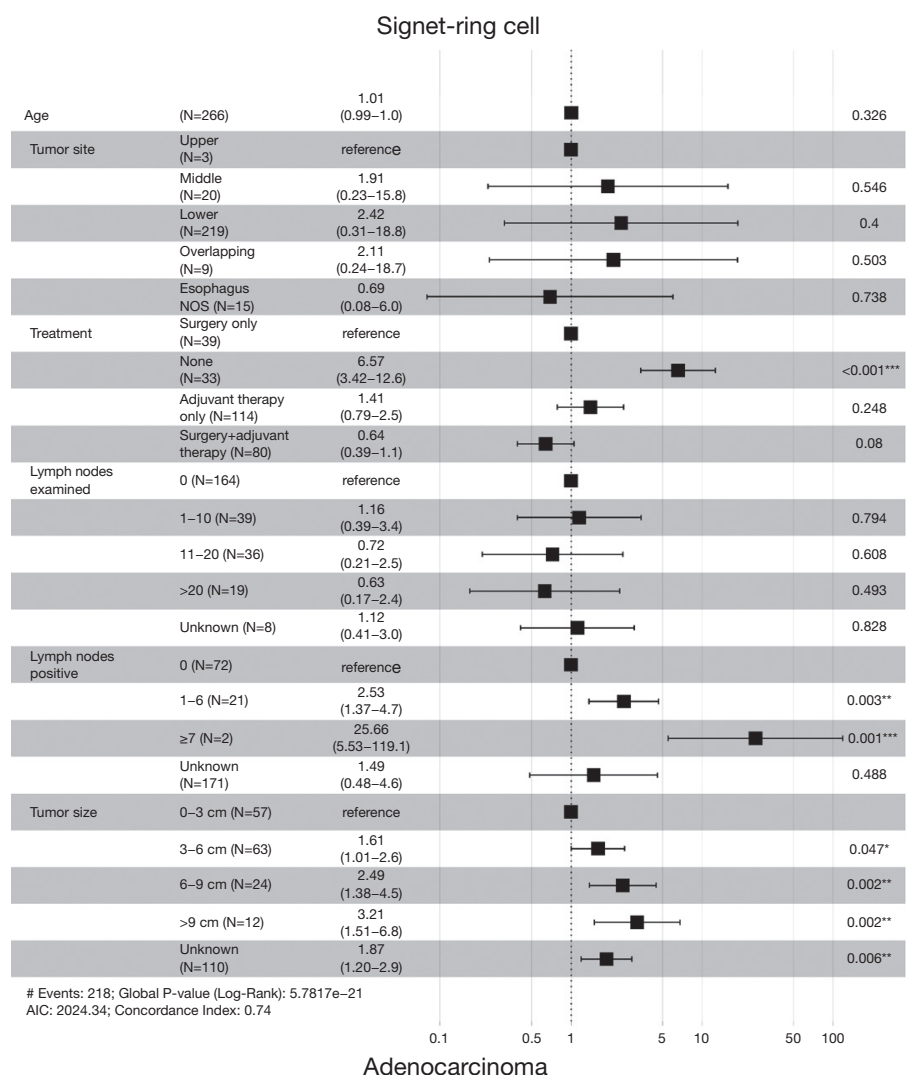

B

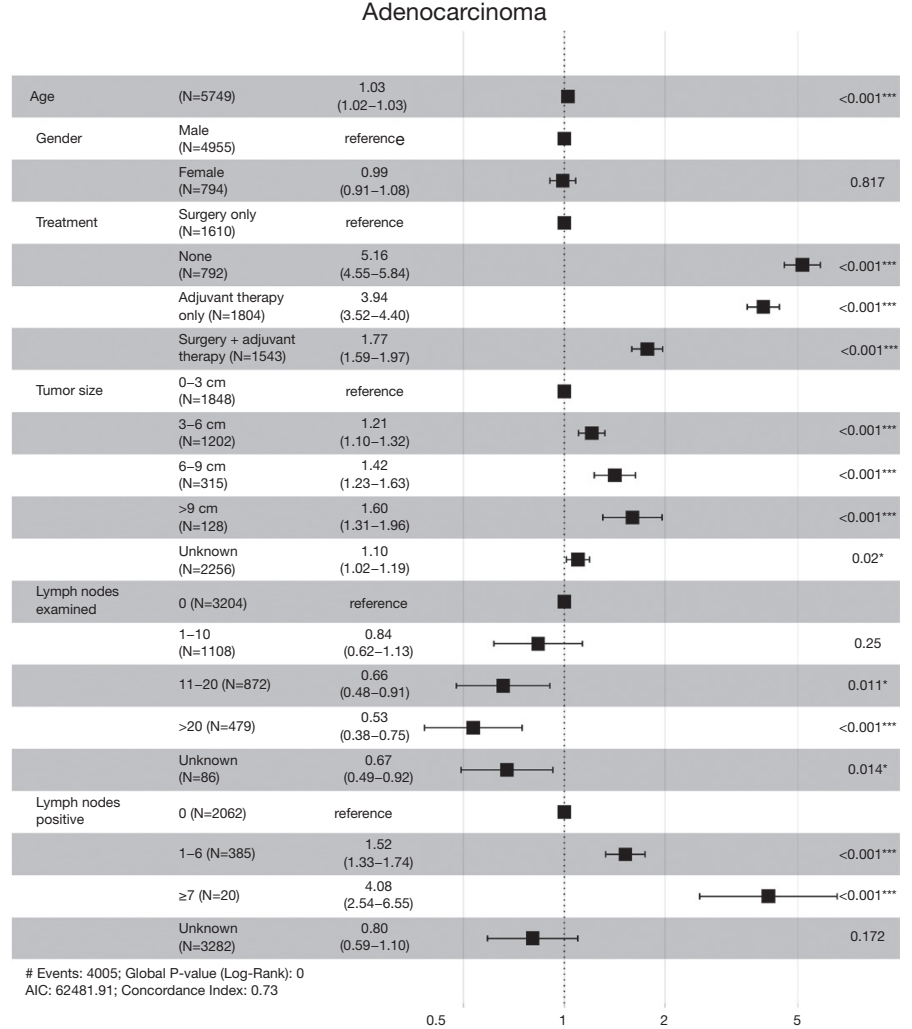

Figure 5 Forest plot of the multivariate Cox proportional hazard regression model analysis of the risk factors of OS for the 2 pathological types in the early stage. (A) Signet-ring cell, (B) adenocarcinoma. *, $\mathrm{P}<0.05$; **, $\mathrm{P}<0.01$; ${ }^{* * *}, \mathrm{P}<0.001$. OS, overall survival. 
Table 5 Univariate Cox proportional hazard regression model analysis of risk factors of OS in the late stage

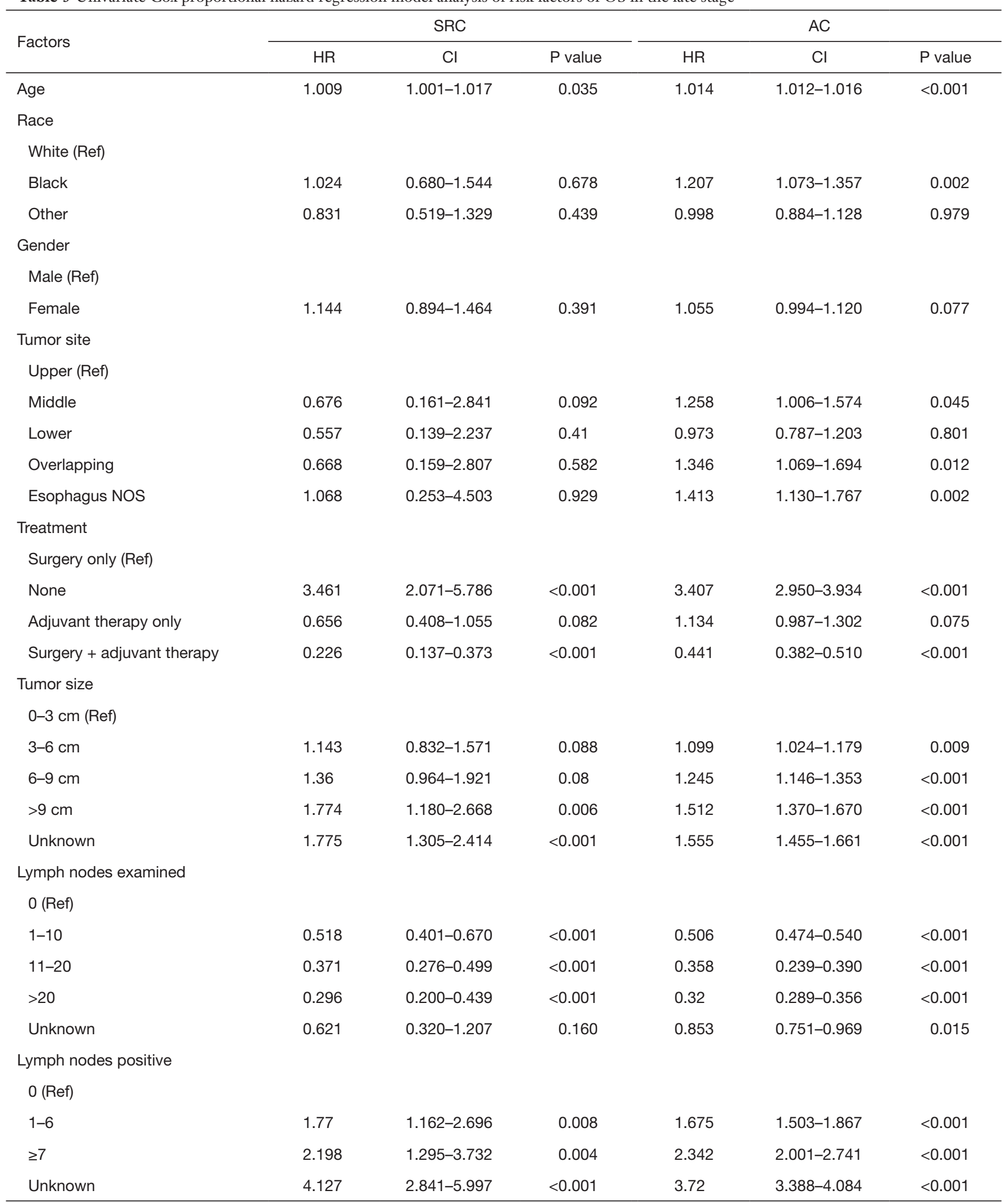

OS, overall survival; SRC, signet ring cell carcinoma; AC, adenocarcinoma; NOS, not otherwise specified. 
A

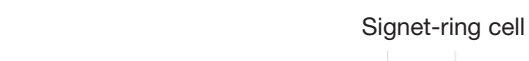

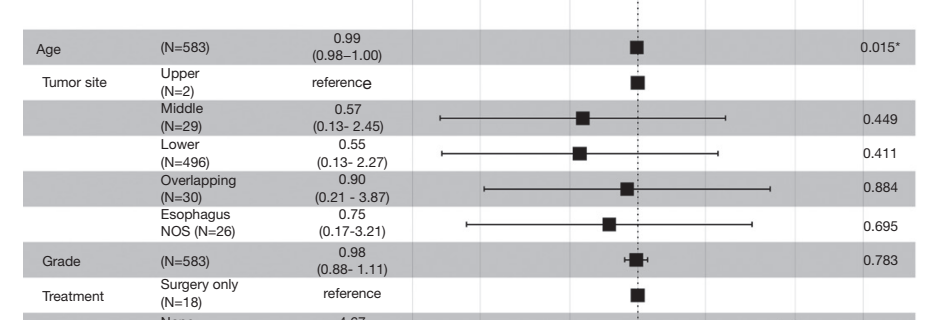
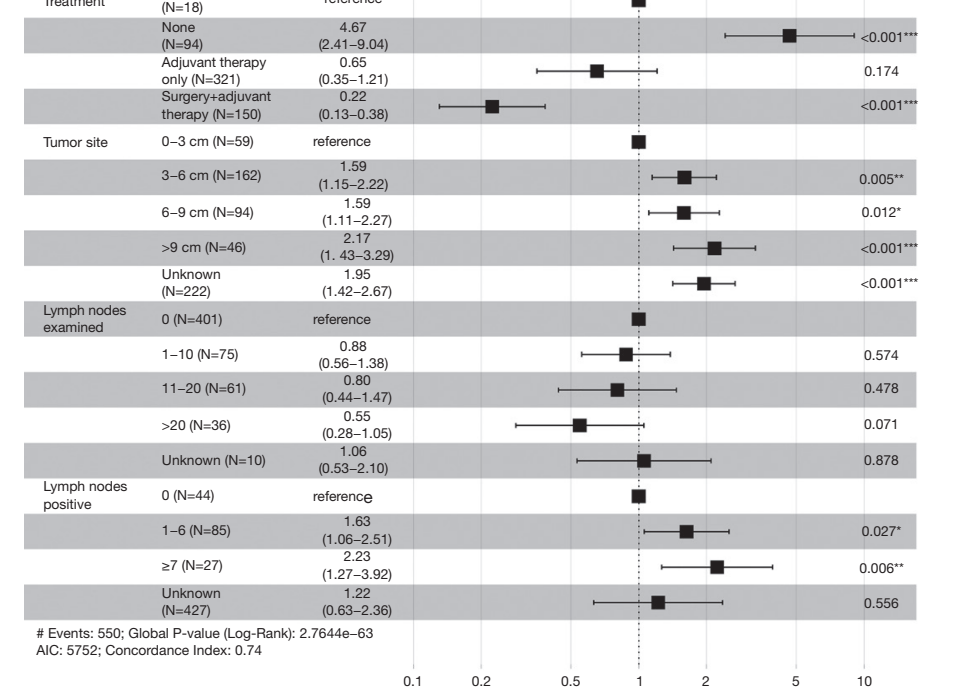

B
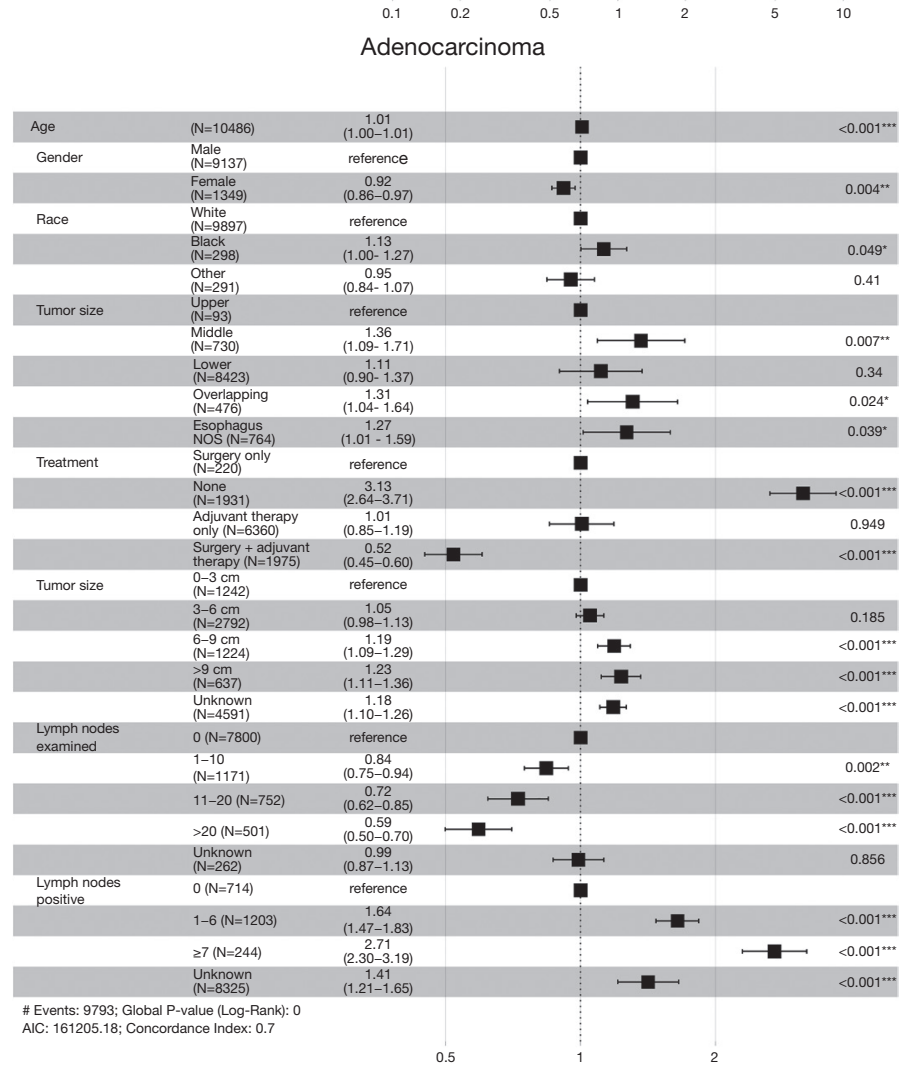

Figure 6 Forest plot of the multivariate Cox proportional hazard regression model analysis of the risk factors of OS for the 2 pathological types in the late stage. (A) Signet-ring cell, (B) adenocarcinoma. ${ }^{*}, \mathrm{P}<0.05 ;{ }^{* *}, \mathrm{P}<0.01 ;{ }^{* *}, \mathrm{P}<0.001$. OS, overall survival. 
overall cohort in this study, surgery plus adjuvant therapy had a worse OS than surgery alone (HR: 1.151, 95\% CI: $1.061-1.247, \mathrm{P}<0.001)$. This result seems to contradict previous studies, though when we conducted a subgroup analysis according to stage, the results showed that the effect of surgery alone was best at the early stage for AC, while late-stage $\mathrm{AC}$ should be treated with surgery combined with adjuvant therapy, which is obviously in line with the current treatment standard (2). We hypothesize that this may be due to the fact that the outcomes of surgery alone at the early stage are particularly good and mask the overall cohort outcomes. However, for SRC at the early stage, the particular treatment is uncertain and may be limited by a small number of cases. None of the previous studies conducted a subgroup analysis related to treatment by stage. The log-rank results of this study (Figure $4 A$ ) showed that there was no significant difference in prognosis between surgery alone and surgery combined with adjuvant therapy at the early stage for SRC $(\mathrm{P}=0.896)$. In the multivariate Cox risk model analysis of SRC (Figure $5 A$ ), surgery combined with adjuvant therapy seemed to have a tendency for better OS than surgery alone (HR: 0.64, 95\% CI: 0.39 1.1, $\mathrm{P}=0.08$ ), although the difference was not statistically significant. This finding is interesting, at least for the early diagnosis of AC and SRC, and it also confirms the need for adjuvant treatment in advanced patients, although there had been limited studies nor guidelines focusing on the chemotherapy regimens for SRC. Nowadays, targeted therapy plays an important role in the treatment process of locally advanced or metastatic AC. For example, the TOGA results showed a survival benefit from trastuzumab plus chemotherapy in HER2-positive patients (HR: 0.74; 95\% CI: 0.60 to $0.91, \mathrm{P}=0.0046$ ) (23). The results of the international phase III RAINBOW trial showed that patients who received ramucirumab plus paclitaxel had a significantly longer median OS (9.63 months) compared to those who received paclitaxel alone (7.36 months, $\mathrm{P}<0.0001)$ (24). Furthermore, the PD-L1 antibody, nivolumab, also helped improve the median OS compared to patients who received chemotherapy alone (10.9 vs. 8.4 months, $\mathrm{P}=0.019$ ) (25). However, no studies have been conducted to confirm the effect of targeted therapy on SRC.

It is important to note that, although no information on surgical margins was available in this study, previous studies have shown that SRC has a higher R1/R2 resection rate, a higher number of positive lymph nodes, and is independently associated with a poorer prognosis
$(6,9,11-13,22)$. Our study corroborates these findings and seems to be consistent with the early trend of SRC requiring surgery combined with adjuvant therapy. In addition, the variable of the number of dissected lymph nodes was innovatively included in this study. In the multivariate Cox risk model for SRC, more examined lymph nodes had a better OS trend, while for AC, the number of dissected lymph nodes was an independent prognostic factor. A retrospective study of 4,882 patients with EC also included from the SEER database (26) adopted the grouping method of the number of lymph nodes dissected, similar to that in this study $(0,11,12-29, \geq 30)$. The results showed that the mortality rate could be improved when the number of lymph nodes dissected was $\geq 12$. When this value increased to more than 30 , both all-cause and cancer-specific survival could achieve the best effect. A recent study by Guo et al. including 139 patients who received preoperative chemoradiotherapy followed by surgery showed that resection of 13-29 lymph nodes was associated with improved survival (27). Similarly, in both the overall cohort and subcohort in this study, multivariate Cox results showed that $\geq 20$ dissected lymph nodes were the most beneficial for OS, although the number of examined lymph nodes was not an independent risk factor for the SRC cohort. Although there was no accepted standard of surgical procedure, we suggested that extensive surgery should be performed for SRC.

Tumor size seems to be a controversial predictor of prognosis, so the AJCC staging system has never included this variable. However, many studies have shown that tumor size is an independent prognostic factor $(28,29)$, and the larger the tumor, the worse the survival will be. In the subgroup analysis, Wang et al. (29) found that the predictive value of tumor length was significant in patients with $\mathrm{T} 1$ or $\mathrm{T} 2$ disease $(\mathrm{P}<0.001)$, $\mathrm{T} 3$ or $\mathrm{T} 4$ disease $(\mathrm{P}=0.029)$, and patients with $\mathrm{N} 0$ disease $(\mathrm{P}<0.001)$, but not for patients with $\mathrm{N} 1, \mathrm{~N} 2$, or $\mathrm{N} 3$ disease. The results of Zhang et al.'s study (28) showed that tumor size was significantly correlated with $T$ stage, with a correlation coefficient of 0.43 $(\mathrm{P}<0.001)$, and tumor size was not associated with prognosis at the $\mathrm{T} 4$ stage $(\mathrm{P}>0.1)$. Similarly, in this study, tumor size was an independent risk factor for the overall cohort, and the results were the same after subgroup analysis based on stage, with $\geq 9 \mathrm{~cm}$ having the worst prognosis.

In a nutshell, we still recommend diagnosing SRC according to WHO histology classification at present, and we suggested that SRC should receive surgery plus adjuvant 
therapy but not surgery alone even at early stage.

To the best of our knowledge, this is the only study to discuss the different treatment methods of SRC and AC by stage. Limited by the low detection rate of SRC, this study is the largest retrospective study to compare the differences between SRC and AC characteristics. However, the limitations of this study lie in its retrospective nature. Firstly, the diagnosis time span of the included cases was large, suggesting that treatment level may have introduced bias to the outcomes. Secondly, the SEER database includes the data of many medical centers in the United States, and different medical centers have different treatment methods, though there is no relevant information on this in the database. Finally, for SRC, the data on surgical margins seemed to be a valid indicator, but the information was not included in the database. Missing data is certainly a disadvantage of this study. Instead of interpolating the missing data, we included the missing data as a subgroup in the analysis, as we believe that interpolation of lost data also has certain risks and bias.

\section{Conclusions}

$\mathrm{SRC}$ is an independent risk factor, with a higher grade of differentiation, later stage, larger tumor size, more positive lymph nodes, and poorer prognosis. At the same time, the diagnosis of SRC is very necessary, because it always means more intervention. Early SRC surgery combined with adjuvant therapy has a good prognostic trend, and early AC surgery alone is recommended, while late AC surgery combined with adjuvant or neoadjuvant therapy is the best treatment. Combined with the results of previous studies, the $\mathrm{R} 1 / \mathrm{R} 2$ resection rate of SRC is higher, the tumor size is larger, and the number of positive lymph nodes is greater. During the operation, the surgical scope of SRC should be expanded and more lymph nodes should be carefully dissected for examination, in order to achieve a better prognosis of patients.

\section{Acknowledgments}

Funding: None.

\section{Footnote}

Reporting Checklist: The authors have completed the STROBE reporting checklist. Available at https://dx.doi. org/10.21037/jgo-21-445

Conflicts of Interest: All authors have completed the ICMJE uniform disclosure form (available at https://dx.doi. org/10.21037/jgo-21-445). The authors have no conflicts of interest to declare.

Ethical Statement: The authors are accountable for all aspects of the work in ensuring that questions related to the accuracy or integrity of any part of the work are appropriately investigated and resolved. This study was conducted in accordance with the Declaration of Helsinki (as revised in 2013). Institutional ethical approval and informed consent were waived.

Open Access Statement: This is an Open Access article distributed in accordance with the Creative Commons Attribution-NonCommercial-NoDerivs 4.0 International License (CC BY-NC-ND 4.0), which permits the noncommercial replication and distribution of the article with the strict proviso that no changes or edits are made and the original work is properly cited (including links to both the formal publication through the relevant DOI and the license). See: https://creativecommons.org/licenses/by-nc-nd/4.0/.

\section{References}

1. Bray F, Ferlay J, Soerjomataram I, et al. Global cancer statistics 2018: GLOBOCAN estimates of incidence and mortality worldwide for 36 cancers in 185 countries. CA Cancer J Clin 2018;68:394-424.

2. NCCN Clinical Practice Guidelines in OncologyEsophageal and Esophagogastric Junction Cancers (2021 Version 2) [EB/OL].

3. Allemani C, Matsuda T, Di Carlo V, et al. Global surveillance of trends in cancer survival 2000-14 (CONCORD-3): analysis of individual records for 37513025 patients diagnosed with one of 18 cancers from 322 population-based registries in 71 countries. Lancet 2018;391:1023-75.

4. Bleaney CW, Barrow M, Hayes S, et al. The relevance and implications of signet-ring cell adenocarcinoma of the oesophagus. J Clin Pathol 2018;71:201-6.

5. Jass JR, Sobin LH, Watanabe H. The World Health Organization's histologic classification of gastrointestinal tumors. A commentary on the second edition. Cancer 1990;66:2162-7. 
6. Nafteux PR, Lerut TE, Villeneuve PJ, et al. Signet ring cells in esophageal and gastroesophageal junction carcinomas have a more aggressive biological behavior. Ann Surg 2014;260:1023-9.

7. Yendamuri S, Huang M, Malhotra U, et al. Prognostic implications of signet ring cell histology in esophageal adenocarcinoma. Cancer 2013;119:3156-61.

8. Chen L, Liu X, Gao L, et al. The clinicopathological features and prognosis of signet ring cell carcinoma of the esophagus: A 10-year retrospective study in China. PLoS One 2017;12:e0176637.

9. Tang A, Rappaport J, Raja S, et al. Signet Ring Cell Histology Confers Worse Overall Survival in Treated Esophageal Adenocarcinoma. Ann Thorac Surg 2021;111:214-22.

10. Solomon D, Abbas M, Feferman Y, et al. Signet Ring Cell Features are Associated with Poor Response to Neoadjuvant Treatment and Dismal Survival in Patients with High-Grade Esophageal Adenocarcinoma. Ann Surg Oncol 2021. [Epub ahead of print]. doi: 10.1245/s10434021-09644-1.

11. Sathe TS, Resio BJ, Hoag JR, et al. Surgically Managed Signet Ring Cell Esophageal Carcinomas in the National Cancer Database. Ann Thorac Surg 2020;109:1656-62.

12. Khan N, Donohoe CL, Phillips AW, et al. Signet ring gastric and esophageal adenocarcinomas: characteristics and prognostic implications. Dis Esophagus 2020;33:doaa016.

13. Gronnier C, Bekkar S, Messager M, et al. Is There a Role for Preoperative Chemoradiation in Esophageal Signet Ring Cell Adenocarcinomas? Ann Thorac Surg 2015;99:2253-4.

14. Corsini EM, Foo WC, Mitchell KG, et al. Esophageal adenocarcinoma with any component of signet ring cells portends poor prognosis and response to neoadjuvant therapy. J Thorac Cardiovasc Surg 2020. [Epub ahead of print]. doi: 10.1016/j.jtcvs.2020.08.108.

15. Palmieri LJ, Dermine S, Abou Ali E, et al. Early esophageal signet ring cell carcinoma: A contraindication to endoscopic resection? Clin Res Hepatol Gastroenterol 2020;44:e98-e102.

16. Wan Z, Huang Z, Chen L. Survival predictors associated with signet ring cell carcinoma of the esophagus (SRCCE): A population-based retrospective cohort study. PLoS One 2017;12:e0181845.

17. Chirieac LR, Swisher SG, Correa AM, et al. Signetring cell or mucinous histology after preoperative chemoradiation and survival in patients with esophageal or esophagogastric junction adenocarcinoma. Clin Cancer Res 2005;11:2229-36.

18. Schmidt T, Sicic L, Blank S, et al. Prognostic value of histopathological regression in 850 neoadjuvantly treated oesophagogastric adenocarcinomas. Br J Cancer 2014;110:1712-20.

19. Patel VR, Hofstetter WL, Correa AM, et al. Signet ring cells in esophageal adenocarcinoma predict poor response to preoperative chemoradiation. Ann Thorac Surg 2014;98:1064-71.

20. The Royal College of Pathologists. Standards and datasets for reporting cancers. Dataset for the histopathological reporting of oesophageal carcinoma. 2nd edn: The Royal College of Pathologists[J]. 2007.

21. van Hootegem SJM, Smithers BM, Gotley DC, et al. The Impact of Signet Ring Cell Differentiation on Outcome in Patients with Esophageal and Gastroesophageal Junction Adenocarcinoma. Ann Surg Oncol 2019;26:2375-84.

22. Wu SG, Chen XT, Zhang WW, et al. Survival in signet ring cell carcinoma varies based on primary tumor location: a Surveillance, Epidemiology, and End Results database analysis. Expert Rev Gastroenterol Hepatol 2018;12:209-14.

23. Sihag S, Ku GY, Tan KS, et al. Safety and feasibility of esophagectomy following combined immunotherapy and chemoradiotherapy for esophageal cancer. J Thorac Cardiovasc Surg 2021;161:836-843.e1.

24. Wilke H, Muro K, Van Cutsem E, et al. Ramucirumab plus paclitaxel versus placebo plus paclitaxel in patients with previously treated advanced gastric or gastro-oesophageal junction adenocarcinoma (RAINBOW): a double-blind, randomised phase 3 trial. Lancet Oncol 2014;15:1224-35.

25. Kato K, Cho BC, Takahashi M, et al. Nivolumab versus chemotherapy in patients with advanced oesophageal squamous cell carcinoma refractory or intolerant to previous chemotherapy (ATTRACTION-3): a multicentre, randomised, open-label, phase 3 trial. Lancet Oncol 2019;20:1506-17.

26. Groth SS, Virnig BA, Whitson BA, et al. Determination of the minimum number of lymph nodes to examine to maximize survival in patients with esophageal carcinoma: data from the Surveillance Epidemiology and End Results database. J Thorac Cardiovasc Surg 2010;139:612-20.

27. Guo JC, Lin CC, Huang TC, et al. Number of Resected Lymph Nodes and Survival of Patients with Locally Advanced Esophageal Squamous Cell Carcinoma 
Receiving Preoperative Chemoradiotherapy. Anticancer Res 2018;38:1569-77.

28. Zhang X, Wang Y, Qu P, et al. Prognostic Value of Tumor Length for Cause-Specific Death in Resectable Esophageal Cancer. Ann Thorac Surg 2018;106:1038-46.

Cite this article as: Peng Z, Li F, Cheng Z, Kai W, Song Z. Comparative analysis of clinical, treatment, and survival characteristics of signet ring cell and adenocarcinoma of esophagus. J Gastrointest Oncol 2021;12(4):1643-1660. doi: 10.21037/jgo-21-445
29. Wang BY, Goan YG, Hsu PK, et al. Tumor length as a prognostic factor in esophageal squamous cell carcinoma. Ann Thorac Surg 2011;91:887-93.

(English Language Editor: C. Betlazar-Maseh) 